\title{
Patients' Perception toward Medical Students' Involvement in Their Surgical Care: Single Center Study
}

\author{
Talal Al-Khatib, ${ }^{1}$ Sanaa Bin Othman, ${ }^{2}$ and Basem El-deek ${ }^{3,4}$ \\ ${ }^{1}$ Department of Otolaryngology-Head \& Neck Surgery, Faculty of Medicine, King Abdulaziz University, Jeddah, Saudi Arabia \\ ${ }^{2}$ Faculty of Medicine, King Abdulaziz University, Jeddah, Saudi Arabia \\ ${ }^{3}$ Department of Medical Education, Faculty of Medicine, King Abdulaziz University, Jeddah, Saudi Arabia \\ ${ }^{4}$ Mansoura University, Mansoura, Egypt \\ Correspondence should be addressed to Talal Al-Khatib; talkhatib@gmail.com
}

Received 23 January 2016; Revised 24 June 2016; Accepted 10 August 2016

Academic Editor: Connie M. Wiskin

Copyright (C) 2016 Talal Al-Khatib et al. This is an open access article distributed under the Creative Commons Attribution License, which permits unrestricted use, distribution, and reproduction in any medium, provided the original work is properly cited.

Objectives. To investigate patients' perception regarding medical students' role in the operating theatre. Methods. A cross-sectional study was conducted on a randomly selected sample at King Abdulaziz University Hospital. Results. 131 participated in this study. 77 of the participants were females and 50 participants were males. $46.4 \%$ think that it was important for the future doctors to be in theater during surgery. $60.2 \%$ thought that medical students only observed surgeons in the theatre and $39 \%$ thought that medical students performed minor procedures in the theatre. Conclusion. Patients underestimated the importance of medical students' attendance and involvement in theatre compared to bedside teaching and outpatient clinics. Patients believed that medical students should obtain their consent prior to observing them in the theatre.

\section{Introduction}

Medical students' communication with real patients affects greatly their learning process specially on improving their skill of linking between clinical experience and theoretical knowledge [1, 2]. As a result, patients have a fundamental role in the medical education process. This human communication will help the medical students' to articulate the knowledge about diseases and practice clinical reasoning in a wide range. Therefore, real patients will always be the best resource in medical education. Patient perceptions toward medical students will be primarily based on personal experience or their surrounding experience; thus, this is considered a great way to evaluate medical students' attitude. In addition, it is a great way to give feedback to medical students about their communication skills and in reassuring medical students that their presence and their contribution to patient care are held positively by patients $[3,4]$. This virtuous cycle will give the patients the opportunity to be a valid part as an educator by using the patients altruism which is found to be the main reason why patients like to contribute in the medical education $[5,6]$. Moreover, it might reflect positively on them physically and emotionally. Studies have found that patients' willingness to accept medical students decreased when the extent of care gets more invasive [7, 8]. This raises the wondering about patient's perception and acceptance of medical students in theatre-based teaching, especially if we considered the variation and complexity of patients comfort levels across different settings since it is more complex in specialties like obstetrics and gynecology $[7,9,10]$. This might become more complicated because patients feel particularly in the operation situation and their awareness about the surroundings is limited. This can increase their apprehension about the reality of medical students' role in the theatre.

\section{Methodology}

A cross-sectional study was conducted on a randomly selected sample at King Abdulaziz University Hospital in the preanesthesia clinic waiting rooms. All patients booked for surgery have to visit preanesthesia clinic before their procedure [11]. All participants were asked to complete 
TAble 1: Participant demographic data.

\begin{tabular}{|c|c|c|c|c|}
\hline & $\begin{array}{l}\text { Male } \\
n(\%)\end{array}$ & $\begin{array}{c}\text { Female } \\
n(\%)\end{array}$ & $P$ value & $\begin{array}{l}\text { Total } \\
n(\%)\end{array}$ \\
\hline \multicolumn{5}{|l|}{ Nationality } \\
\hline (i) Saudi & $26(52 \%)$ & $54(70.1 \%)$ & \multirow{2}{*}{0.039} & $80(63 \%)$ \\
\hline (ii) Non-Saudi & $24(48 \%)$ & $23(29.9 \%)$ & & $47(37 \%)$ \\
\hline \multicolumn{5}{|l|}{ Education } \\
\hline (i) No formal education & $2(4 \%)$ & $5(6.4 \%)$ & \multirow{5}{*}{0.321} & $7(5.5 \%)$ \\
\hline (ii) Elementary & $2(4 \%)$ & $7(9 \%)$ & & $9(7 \%)$ \\
\hline (iii) Intermediate & $3(6 \%)$ & $11(14.4 \%)$ & & $14(10.9 \%)$ \\
\hline (iv) Secondary & $17(34 \%)$ & $18(23.1 \%)$ & & $35(27.3 \%)$ \\
\hline (v) University and above & $26(52 \%)$ & $37(47.4 \%)$ & & $63(49.2 \%)$ \\
\hline \multicolumn{5}{|l|}{ Marital status } \\
\hline (i) Single & $13(26.5 \%)$ & $7(9 \%)$ & \multirow{4}{*}{0.042} & $20(15.7 \%)$ \\
\hline (ii) Married & $35(71.4 \%)$ & $68(87.2 \%)$ & & $103(81.1 \%)$ \\
\hline (iii) Divorced & $0(0 \%)$ & $2(2.6 \%)$ & & $2(1.6 \%)$ \\
\hline (iv) Widow & $1(2 \%)$ & $1(1.3 \%)$ & & $2(1.6 \%)$ \\
\hline \multicolumn{5}{|l|}{ Are you } \\
\hline (i) Patient & $35(70 \%)$ & $54(70.1 \%)$ & \multirow{2}{*}{0.988} & $89(70.1 \%)$ \\
\hline (ii) Guardian & $15(30 \%)$ & $23(29.9 \%)$ & & $38(29.9 \%)$ \\
\hline
\end{tabular}

anonymous written questionnaire while they are waiting their turn in the clinic. The data collection was done in 12 separate days from July to August 2013. Study sample size was calculated by OpenEpi based on the average number of patients who attended preanesthesia clinic every day for 4 weeks in the month that proceeded data collection with exclusion of weekend days. The tool of the study was a questionnaire consisting of 5 pages of 31 questions that vary among the participant demographic data, Yes/No questions, multiple choice questions, and open-ended questions that allow the participants to express their opinion by their own words. The questionnaire was designed to allow adult participants to answer and the guardians to answer on behalf of their children. The questionnaire design was taken from the medical literature on the same topic with some modification and some new questions that serve the study purposes. Three consultants who are not involved in the study to ensure content validity of the questionnaire revised the questionnaire. A pilot study was done on ten patients to test the feasibility of the questionnaire. The consent was written in a small box at the beginning of the questionnaire that asks the potential participant to gently fill the questionnaire, the time that will be needed to finish it ( 5 minutes), their ability to accept or reject the participation, their ability to drop out if they decide that before the completion of the questionnaire, and the confidentiality of the information. This was combined with an informed consent that was taken during the distribution of the questionnaire among the participants by the coinvestigator of the study. The ethical approval was obtained from King Abdulaziz University research ethics committee. The questionnaire data were entered into a Microsoft Excel sheet and the data was analyzed by SPSS program (version 16).

\section{Results}

One hundred and thirty-one participated in this study. Patients' demographics are shown in Table 1. Seventy-eight (61.9\%) think that it is very important for the future doctors to be present while the patient is talking to the doctor about their medical problem. Seventy-five (58.6\%) think that it is very important for future doctors to examine patients. Fifty-eight (46.4\%) think that it is very important for future doctors to be in the operating room during surgery. Eighty-two (65.1\%) will permit medical students to be present when they will have surgery in the operating room. Patients' perception about the role of medical students and residents in the operation theatre is shown in Table 2. Thirty-six (29.3\%) thought that the type of surgery will affect their decision about their willingness of medical students' involvement during the surgery. Fifty $(39.4 \%)$ believed that they have the right to refuse medical students involvement in their health care. Fifty (40\%) females will allow medical students to observe them while the doctor examined them. Thirty-six (28.8\%) will allow medical students to watch them depending on which part of their body was being examined. Seven (5.6\%) will allow medical students to watch if the student was male and depending on which part of their body is being examined. Twenty-two (17.6\%) will allow medical students to watch if the student was female and depending on which part of their body was being examined. Ten (8\%) will refuse medical students to watch while the doctor examines them. One hundred and fourteen (91.2\%) will allow medical students to take a detailed history from them. Forty-two (34.1\%) will allow medical student to examine them and 32 (26\%) will allow medical student to examine them depending on which part of their body was being examined. Seven (5.7\%) will allow medical student to examine them if the medical student 
TABLE 2: Patients' perception about the role of medical students and residents in the operation theatre.

\begin{tabular}{|c|c|c|c|c|}
\hline & $\begin{array}{l}\text { Male } \\
n(\%)\end{array}$ & $\begin{array}{c}\text { Female } \\
n(\%)\end{array}$ & $P$ value & $\begin{array}{l}\text { Total } \\
n(\%)\end{array}$ \\
\hline \multicolumn{5}{|c|}{$\begin{array}{l}\text { Would you permit medical students to be present in the operation room when you are } \\
\text { having a surgery? }\end{array}$} \\
\hline Yes & $40(80 \%)$ & $42(55.3 \%)$ & 0.004 & $82(65.1 \%)$ \\
\hline \multicolumn{5}{|c|}{ What exactly do you think medical students do in the operation room? } \\
\hline (i) Observe the surgeons & $29(61.7 \%)$ & $45(59.2 \%)$ & 0.784 & $74(60.2 \%)$ \\
\hline (ii) Participate in the surgery & $2(4.3 \%)$ & $5(6.65)$ & 0.589 & $7(5.7 \%)$ \\
\hline (iii) Do a minor procedure & $19(40.4 \%)$ & $29(38.2)$ & 0.802 & $48(39 \%)$ \\
\hline \multicolumn{5}{|c|}{ What exactly do you think residents do in the operating room? } \\
\hline (i) Observe the surgeons & $17(35.4 \%)$ & $21(27.3 \%)$ & 0.336 & $38(30.4 \%)$ \\
\hline (ii) Participate in the surgery & $18(37.5 \%)$ & $30(39 \%)$ & 0.870 & $48(38.4 \%)$ \\
\hline (ii) Do a minor procedure & $17(35.45 \%)$ & $30(39 \%)$ & 0.691 & $47(37.6 \%)$ \\
\hline \multicolumn{5}{|c|}{$\begin{array}{l}\text { Do you believe that medical students should specifically obtain patient consent prior to } \\
\text { becoming observers in the operating room? }\end{array}$} \\
\hline Yes & $39(79.6 \%)$ & $63(82.9 \%)$ & 0.642 & $102(81.6 \%)$ \\
\hline
\end{tabular}

TABLE 3: Views of patients' previous experience with medical students.

\begin{tabular}{|c|c|c|c|c|}
\hline & $\begin{array}{l}\text { Male } \\
n(\%)\end{array}$ & $\begin{array}{c}\text { Female } \\
n(\%)\end{array}$ & $P$ value & $\begin{array}{l}\text { Total } \\
n(\%)\end{array}$ \\
\hline \multicolumn{5}{|c|}{$\begin{array}{l}\text { Have you ever come in contact with a medical student during your visit/admission in the } \\
\text { hospital? }\end{array}$} \\
\hline Yes & $23(46 \%)$ & $42(55 \%)$ & 0.309 & $61(48.4 \%)$ \\
\hline \multicolumn{5}{|c|}{ If yes, what did the medical student do for you? } \\
\hline (i) Asked me questions only & $15(62.5 \%)$ & $28(57.1 \%)$ & 0.662 & $43(58.9 \%)$ \\
\hline (ii) Observed doctors examine me & $11(45.8 \%)$ & $24(49 \%)$ & 0.800 & $35(47.9 \%)$ \\
\hline (iii) Examined me by him/herself & $15(62.5 \%)$ & $22(44.9 \%)$ & 0.158 & $37(50.7 \%)$ \\
\hline \multicolumn{5}{|c|}{$\begin{array}{l}\text { Did anyone seek your consent before the participation of the student in your } \\
\text { management? }\end{array}$} \\
\hline Yes & $15(42.9 \%)$ & $27(41.5 \%)$ & 0.899 & $42(42 \%)$ \\
\hline \multicolumn{5}{|c|}{ Will the type of surgery affect your decision about the medical student involvement? } \\
\hline Yes & $12(24.5 \%)$ & $24(32.4 \%)$ & 0.343 & $36(29.3 \%)$ \\
\hline \multicolumn{5}{|c|}{ Do you believe that you have the right to refuse medical students? } \\
\hline Yes & $19(38.8 \%)$ & $31(39.7 \%)$ & 0.913 & $50(39.4 \%)$ \\
\hline
\end{tabular}

was a male and depending on which part of their body is being examined. Twenty-three (18.7\%) will allow medical student to examine them and $19(15.4 \%)$ will refuse medical students to examine them. Ten (52.6\%) who answered No will allow medical students to examine them while a doctor was supervising them views patients' previous experience with medical students shown in Table 3.

Ten $(29.4 \%)$ of guardians who were involved on behalf of their children thought that they gain useful information from medical students. Other results of guardians views and their experience with medical students are shown in Table 4.

Seventy-two (56.7\%) think that general appearance and the manner of medical students will affect the level of their cooperation with medical students. Forty-two (37.8\%) found that the presence of medical students made consultation time longer. Forty-nine (45.8\%) had taken useful information from medical students about their health problem. Eighty (78.4\%) found that seeing and dealing with medical students was enjoyable. Patients comfort level toward the number, gender, and medical training year of the medical students is shown in Table 5.

\section{Discussion}

This study was done to evaluate the perception of patients toward medical student involvement in surgical care. We targeted patients who were going to have surgery and guardians whom their children were going to have surgery to guarantee that they would be explicit, honest, and expressive as much as possible about their perception and attitude. We thought that this could decrease hypothetical assumptions that might be headed toward courtesy. 
TABLE 4: Guardians views and their experience with medical students.

\begin{tabular}{|c|c|c|c|c|}
\hline & Patient & Guardian & $P$ value & Total \\
\hline \multicolumn{5}{|l|}{ What did the medical student do for you? } \\
\hline (i) Asked me questions only & $33(58.9 \%)$ & $10(62.5 \%)$ & 0.797 & $43(59.7 \%)$ \\
\hline (ii) Observed doctors examine me & $23(41.1 \%)$ & $11(68.8 \%)$ & 0.050 & $34(47.2 \%)$ \\
\hline (iii) Examined me by him/herself & $29(51.8 \%)$ & $8(50 \%)$ & 0.900 & $37(51.4 \%)$ \\
\hline \multicolumn{5}{|c|}{$\begin{array}{l}\text { Does the medical student provide you with useful information about your health } \\
\text { problem? }\end{array}$} \\
\hline Yes & $40(53.3 \%)$ & $10(29.4 \%)$ & 0.020 & $50(45.9 \%)$ \\
\hline \multicolumn{5}{|c|}{$\begin{array}{l}\text { How important for the training of future doctors do you think it is that medical students } \\
\text { are present while patients are talking to the doctor about their problem? }\end{array}$} \\
\hline (i) Very important & $53(60.9 \%)$ & $26(63.4 \%)$ & 0.051 & $79(61.7 \%)$ \\
\hline (ii) Important & $16(18.4 \%)$ & $13(31.7 \%)$ & & $29(22.7 \%)$ \\
\hline (iii) Not sure & $11(12.6 \%)$ & $0(0 \%)$ & & $11(8.6 \%)$ \\
\hline (iv) Not so important & $4(4.6 \%)$ & $0(0 \%)$ & & $4(3.1 \%)$ \\
\hline (v) Unnecessary & $3(3.4 \%)$ & $2(4.9 \%)$ & & $5(3.9 \%)$ \\
\hline \multicolumn{5}{|c|}{ What exactly do you think residents do in the operating room? } \\
\hline (i) Observe the surgeons & $30(34.5 \%)$ & $8(20 \%)$ & 0.098 & $38(29.9 \%)$ \\
\hline (ii) Participate in the surgery & $37(42.5 \%)$ & $11(27.5 \%)$ & 0.105 & $48(37.8 \%)$ \\
\hline (iii) Do a minor procedure & $27(31 \%)$ & $22(55 \%)$ & 0.010 & $49(38.6 \%)$ \\
\hline
\end{tabular}

TABLE 5: Patients comfort level toward the number, gender, and medical training year of the medical students.

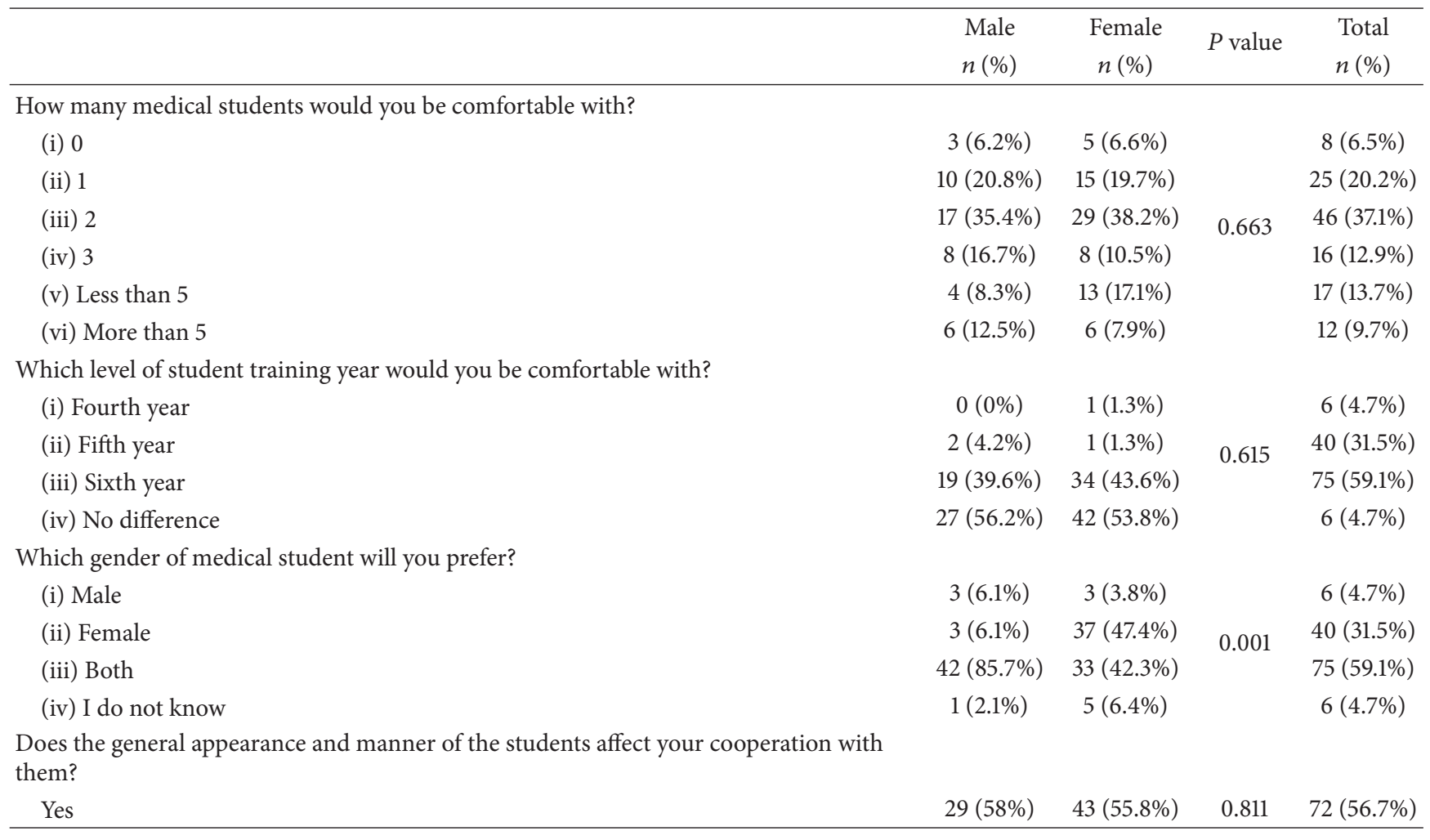

The design of the questions was done to evaluate if there was any variation in patients perception toward medical students in different settings and levels during their hospital course starting from patients' first exposure to medical students by history taking and examination up to being with them in the operating room. The result of our study supports the previous studies that were done in this area. Patients had a positive attitude and perception toward medical students' involvement in their health care. Although Vaughn et al. argued about the lack of clear defined cut points between 
the positive and the negative perceptions, others like Simon et al. found that patients' satisfaction did not increase or decrease when medical students were involved by using two controlled groups for assessment. This positive perception was consistent with previous studies that were done in Saudi Arabia and other Middle East countries [3, 4, 12-14], keeping in consideration that those populations have to some extent similar cultural background and beliefs.

Participants' thoughts that being with them in the operating room is an important part of medical students learning process were the least important compared to being with them during doctor consultation and bedside teaching. As a result, they believe that history taking and examination were more valid for medical students' education. We found that $65.1 \%$ would allow medical students to present in the operation room. In comparison to Ben Salah et al. they had a higher percentage $(90.2 \%)$ regarding permitting the presence of medical students in the operation theatre [12] and the percentage was $57.7 \%$ in Marwan et al. [14]. This perception led us to other essential queries about their perception about the medical students' role in the operating room. They thought that medical students only observed surgeons during surgery followed by doing minor procedure during surgery and a small proportion thought that they participated in the operation itself. Up to the authors' knowledge, no studies were found to evaluate patients' perception toward medical students' role in the operation theatre.

The participants tried to minimize the importance of operating room education for medical students. It might be for the reason that patients' may have concerns about their awareness status in the operation compared to other settings. In addition, fear of incapacity to refuse or to accept the extent of medical students involvement compared to other settings may lead to this perception. Moreover, lack of comprehensive understanding of the surgical procedures that the patient will be involved in will cause more big concerns.

There were no significant results in the pediatric patients except that their guardians mainly thought that the acquisition of history taking skills is the most important for medical student education, which flows with the same adult population perception, although the reasons might differ, causing distress or pain to the child could be the fundamental stimulus to this perception [15].

A systemic review was done to evaluate the patient attitude toward medical students participation across specialties that included 59 studies that strongly agreed on one conclusion: the type of participation of the medical students will affect the overall acceptance of the medical students [8]. Furthermore, Leung and Patil concluded that patient's willingness and acceptance of medical students' involvement in bedside teaching is not a beforehand guarantee toward operating room involvement [16]. As the involvement of the medical students increases, the refusal rate increases $[8,12$, 14]. In other words, we should use these terms (presenting, observing, participating, and interacting) cautiously when asking patients about their willingness to involve medical students' in their health care. Keep in consideration that $81.6 \%$ of our participant thought that medical students should obtain their consent prior to presenting in the operation room, even though all the participants were aware that they were in an academic teaching hospital. Although Santen et al. found that the acceptance of patients to allow medical students do simple procedures on them when they identified and clarified that they are inexperienced students or that this is their first time doing the procedure, $90 \%$ of patients will allow them to do the procedure [17]. Meanwhile, Marwan et al. had only $33.8 \%$ of participants who are willing to let medical students do procedures on them [14]. It is still unclear whether the specification of the procedure influenced Santen et al. result or patients' appreciation of the explicitness of the medical students made them more cooperative. We found that $91.2 \%$ of our study participants have no problem in the involvement of medical students in the part of taking a detailed history from them. However, this opinion decreases to the half in percentage regarding when it came to physical exam. And we think this perception is more likely being guided by privacy maintaining more than concerning about the low medical students skills due to the evidence that this result persists even when medical student only observes them being examined by the attending doctor. In addition, presence and the absence of the supervising doctor did not change this attitude $[3,4,16]$. The research team can link this to the fact that half of the participants thought that two students' involvement during consultation and examination was the best number that will make them feel comfortable. However, this number has not been achieved in everyday real practice that led to more exploration for privacy and more fear from the violation of privacy by medical students' involvement.

In Passaperuma et al., patients were generally comfortable with both male and female medical students, but they were more likely feeling comfortable in dealing with female medical students more than male medical students [7]. However, the research team found that more than the half of the participants felt comfortable in dealing with both male and female medical students equally, followed by preferring female medical students over male medical students. On the other hand, Al Ghobain et al. and Mol et al. found that patients preferred to deal with the gender of their own with $58 \%$ in Riyadh $[6,13]$.

Most of the participants found that dealing with medical students was enjoyable $[12,18,19]$. This might be due to the delightful feeling that people feel when they help others. Even though we did not explore the reasons that might make this experience unpleasant to some people, we can predict that it could be related to previous bad experience, privacy violation, poor communication skills of medical students, or unprofessional attitude by medical students.

In addition, we used intentionally a vague Yes/No question that was used in another study about the effect of medical students manners and appearance in encouraging the participants to be cooperative; then we gave them the chance to clarify their answer with an open-ended question that asked them to explain. As a result, the majority of them (50\%) approximately answered Yes to the Yes/No but the majority did not clarify their answer in the open-ended question and left it empty. The others who clarified their answer commented on the fact that they are looking for 
medical students with good manners to be cooperative and neglect the part of the medical student appearance. The ones who answered about the appearance mainly focused more on the professional appearance that they were expecting it to be achieved from females and neglected male medical students.

Almost half of the participants thought that dealing with medical students helped them gain more information about their illness and their health, which is consistent with another study [20].

Patients' thoughts regarding the role of residents in the operating room compared to medical students was differing significantly. The majority of patient thought that medical students observe surgeons during surgery. However, the percentages almost equally divided between the roles of residents in the operating room, which highlight the confusion that people might have regarding the different medical degrees and doctors' roles according to their degrees.

\section{Appendix}

\section{Questionnaire: Patients' Perception toward Medical Students' Involvement in Their Surgical Care}

Please select the most appropriate answer:

\section{Demographic Data}

Age:

Gender:
(i) Male
(ii) Female

Nationality:
(i) Saudi
(ii) non-Saudi

Educational status:
(i) No formal education
(ii) Elementary
(iii) Intermediate
(iv) Secondary
(v) University and above

Are you:
(i) A patient
(ii) A guardian

Marital status:
(i) Single
(ii) Married
(iii) Divorced
(iv) Widowed

What kind of surgery you will perform?
Have you ever come in contact with a medical student during your visit/admission in the hospital?

(i) Yes

(ii) No

If yes, what did the medical student do for you?

(i) Asked me questions only

(ii) Observed doctors examine me

(iii) Examined me by him/herself

Did anyone seek your consent before the participation of the student in your management?

(i) Yes

(ii) No

Will the type of surgery affect your decision about the medical student involvement?

(i) Yes

(ii) No

If you answered Yes, explain

Do you believe that you have the right to refuse medical students?

(i) Yes

(ii) No

Would you allow a medical student to watch while the doctor examines you?

(i) Yes in all cases

(ii) Yes, depending on which part of my body is being examined

(iii) Yes, if male student

(iv) Yes, if male student and depending on which part of my body is being examined

(v) Yes, if female student

(vi) Yes, if female student and depending on which part of my body is being examined

(vii) No

Would you allow a medical student to take a detailed history from you?

(i) Yes

(ii) No

Would you allow a medical student to examine you?

(i) Yes in all cases

(ii) Yes, depending on which part of my body is being examined

(iii) Yes, if male student 
(iv) Yes, if male student and depending on which part of my body is being examined

(v) Yes, if female student

(vi) Yes, if female student and depending on which part of my body is being examined

(vii) No

If you answered No, would you allow a medical student to examine you with the doctor supervising them?

(i) Yes in all cases

(ii) Yes, depending on which part of my body is being examined

(iii) Yes, if male student

(iv) Yes, if male student and depending on which part of my body is being examined

(v) Yes, if female student

(vi) Yes, if female student and depending on which part of my body is being examined

(vii) No

How many medical students would you be comfortable with?
(i) 0
(ii) 1
(iii) 2
(iv) Less than 5
(v) More than 5

Which level of student training year would you be comfortable with?
(i) Fourth year
(ii) Fifth year
(iii) Sixth year
(iv) No difference

Which gender of medical student will you prefer?
(i) Male
(ii) Female
(iii) Both
(iv) I do not know

Does the general appearance and manner of the students affect your cooperation with them?

(i) Yes

(ii) No

If you answered Yes, what do you think is appropriate appearance for a medical student?

(i) Male

(ii) Female
Does the medical student presence during your consultation make consultation time longer?

(i) Yes

(ii) No

Does the medical student provide you with useful information about your health problem?

(i) Yes

(ii) No

Is seeing a medical student enjoyable?

(i) Yes

(ii) No

How important for the training of future doctors do you think it is that medical students are present while patients are talking to the doctor about their problem?

(i) Very important

(ii) Important

(iii) Not sure

(iv) Not so important

(v) Unnecessary

How important for the future training of doctors do you think it is that medical students examine patients?

(i) Very important

(ii) Important

(iii) Not sure

(iv) Not so important

(v) Unnecessary

How important for the future training of doctors do you think it is that medical students present in the operation room during surgery?

(i) Very important

(ii) Important

(iii) Not sure

(iv) Not so important

(v) Unnecessary

Would you permit medical students to be present in the operation room when you having a surgery?

(i) Yes

(ii) No

Would you permit residents to be present in the operating room when you are having surgery?

(i) Yes

(ii) No 
What exactly do you think medical students do in the operation room?

(i) Observe the surgeons

(ii) Participate in the surgery

(iii) Do a minor procedure

What exactly do you think residents do in the operating room?

(i) Observe the surgeons

(ii) Participate in the surgery

(iii) Do a minor procedure

Do you believe that medical students should specifically obtain patient consent prior to becoming observers in the operating room?

(i) Yes

(ii) No

\section{Competing Interests}

The authors declare that there is no conflict of interests regarding the publication of this manuscript.

\section{References}

[1] A. D. Diemers, D. H. J. M. Dolmans, M. G. M. Verwijnen, E. Heineman, and A. J. J. A. Scherpbier, "Students' opinions about the effects of preclinical patient contacts on their learning," Advances in Health Sciences Education, vol. 13, no. 5, pp. 633647, 2008

[2] R. R. Hemphill, S. A. Santen, C. B. Rountree, and A. R. Szmit, "Patients' understanding of the roles of interns, residents, and attending physicians in the emergency department," Academic Emergency Medicine, vol. 6, no. 4, pp. 339-344, 1999.

[3] H. M. Abdulghani, M. O. Al-Rukban, and S. S. Ahmad, "Patient attitudes towards medical students in Riyadh, Saudi Arabia," Education for Health, vol. 21, no. 2, p. 69, 2008.

[4] R. M. Sayed-Hassan, H. N. Bashour, and A. Y. Koudsi, "Patient attitudes towards medical students at Damascus University teaching hospitals," BMC Medical Education, vol. 12, no. 1, article 13, 2012.

[5] A.-C. Haffling and A. Håkansson, "Patients consulting with students in general practice: survey of patients' satisfaction and their role in teaching," Medical Teacher, vol. 30, no. 6, pp. 622$629,2008$.

[6] S. S. L. Mol, J. H. Peelen, and M. M. Kuyvenhoven, "Patients' views on student participation in general practice consultations: a comprehensive review," Medical Teacher, vol. 33, no. 7, pp. e397-e400, 2011.

[7] K. Passaperuma, J. Higgins, S. Power, and T. Taylor, "Do patients' comfort levels and attitudes regarding medical student involvement vary across specialties?" Medical Teacher, vol. 30, no. 1, pp. 48-54, 2008.

[8] J. L. Vaughn, L. R. Rickborn, and J. A. Davis, "Patients' attitudes toward medical student participation across specialties: a systematic review," Teaching and Learning in Medicine, vol. 27, no. 3, pp. 245-253, 2015.
[9] N. Anfinan, N. Alghunaim, A. Boker et al., "Obstetric and gynecologic patients' attitudes and perceptions toward medical students in Saudi Arabia," Oman Medical Journal, vol. 29, no. 2, pp. 106-109, 2014.

[10] D. Carmody, A. Tregonning, E. Nathan, and J. P. Newnham, "Patient perceptions of medical students' involvement in their obstetrics and gynaecology health care," Australian and New Zealand Journal of Obstetrics and Gynaecology, vol. 51, no. 6, pp. 553-558, 2011.

[11] J. L. Apfelbaum, R. T. Connis, D. G. Nickinovich et al., "Practice advisory for preanesthesia evaluation: an updated report by the American Society of Anesthesiologists Task Force on Preanesthesia Evaluation," Anesthesiology, vol. 116, no. 3, pp. 522-538, 2012.

[12] A. Ben Salah, S. El Mhamdi, I. Bouanene, A. Sriha, and M. Soltani, "Patients' attitude towards bedside teaching in Tunisia," International Journal of Medical Education, vol. 6, pp. 201-207, 2015.

[13] M. Al Ghobain, A. Alghamdi, A. Arab, N. Alaem, T. Aldress, and M. Ruhyiem, "Patients' perceptions towards the participation of medical students in their care," Sultan Qaboos University Medical Journal, vol. 16, no. 2, pp. e224-e229, 2016.

[14] Y. Marwan, M. Al-Saddique, A. Hassan, J. Karim, and M. AlSaleh, "Are medical students accepted by patients in teaching hospitals?" Medical Education Online, vol. 17, no. 1, Article ID 17172, 2012.

[15] R. Pinnock, J. Weller, B. Shulruf, R. Jones, P. Reed, and S. Mizutani, "Why parents and children consent to become involved in medical student teaching," Journal of Paediatrics and Child Health, vol. 47, no. 4, pp. 204-210, 2011.

[16] G. K. K. Leung and N. G. Patil, "Medical students as observers in theatre: is an explicit consent necessary?" Clinical Teacher, vol. 8, no. 2, pp. 122-125, 2011.

[17] S. A. Santen, R. R. Hemphill, C. M. Spanier, and N. D. Fletcher, "'Sorry, it's my first time!' Will patients consent to medical students learning procedures?" Medical Education, vol. 39, no. 4, pp. 365-369, 2005.

[18] K. Coleman and E. Murray, "Patients' views and feelings on the community-based teaching of undergraduate medical students: a qualitative study," Family Practice, vol. 19, no. 2, pp. 183-188, 2002.

[19] M. D. Prislin, E. Morrison, M. Giglio, P. Truong, and S. Radecki, "Patients' perceptions of medical students in a longitudinal family medicine clerkship," Family Medicine, vol. 33, no. 3, pp. 187-191, 2001.

[20] C. Scheffer, F. Edelhuser, D. Tauschel, M. Riechmann, and A. Tekian, "Can final year medical students significantly contribute to patient care? A pilot study about the perception of patients and clinical staff," Medical Teacher, vol. 32 , no. 7, pp. 552-557, 2010. 


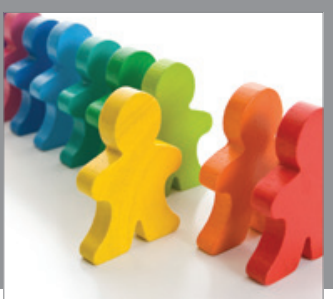

Autism

Research and Treatment
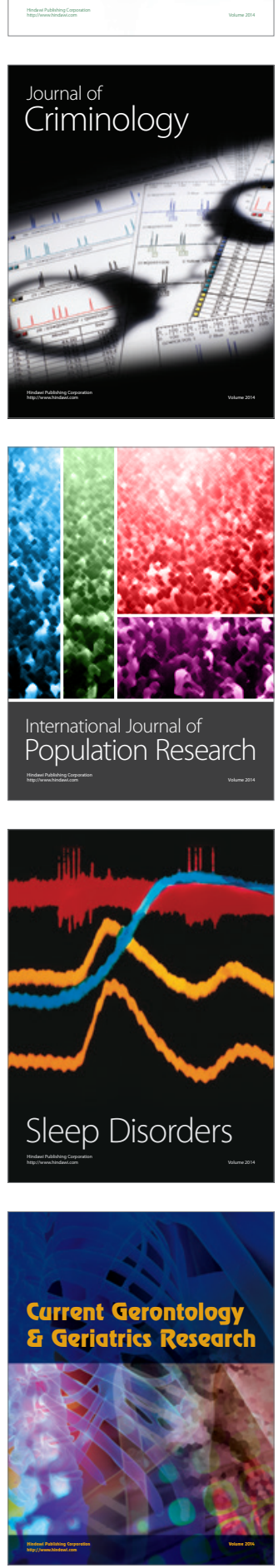

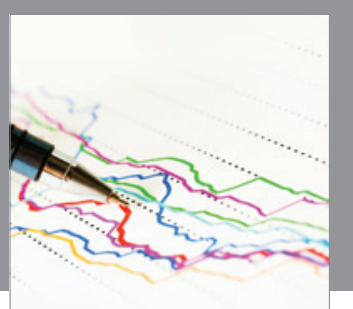

Economics

Research International
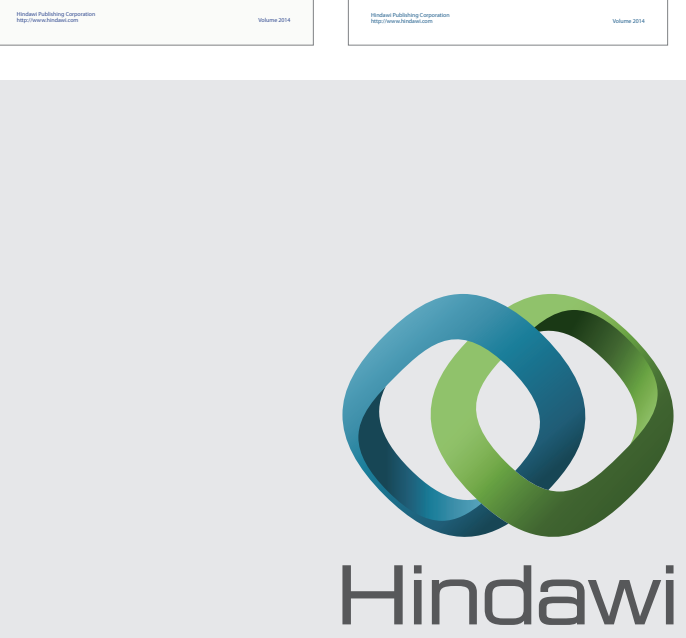

Submit your manuscripts at

http://www.hindawi.com
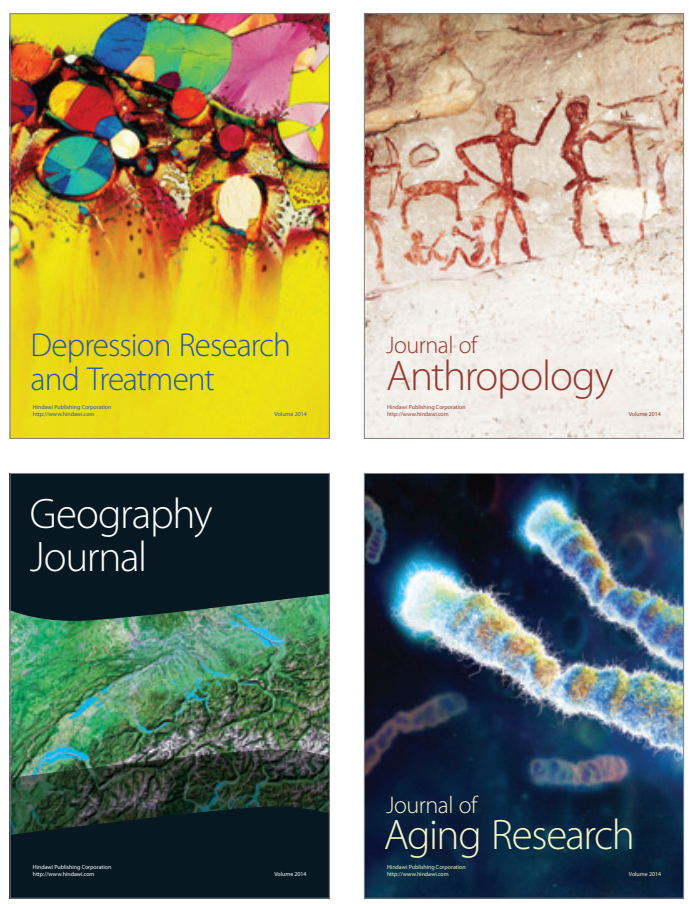
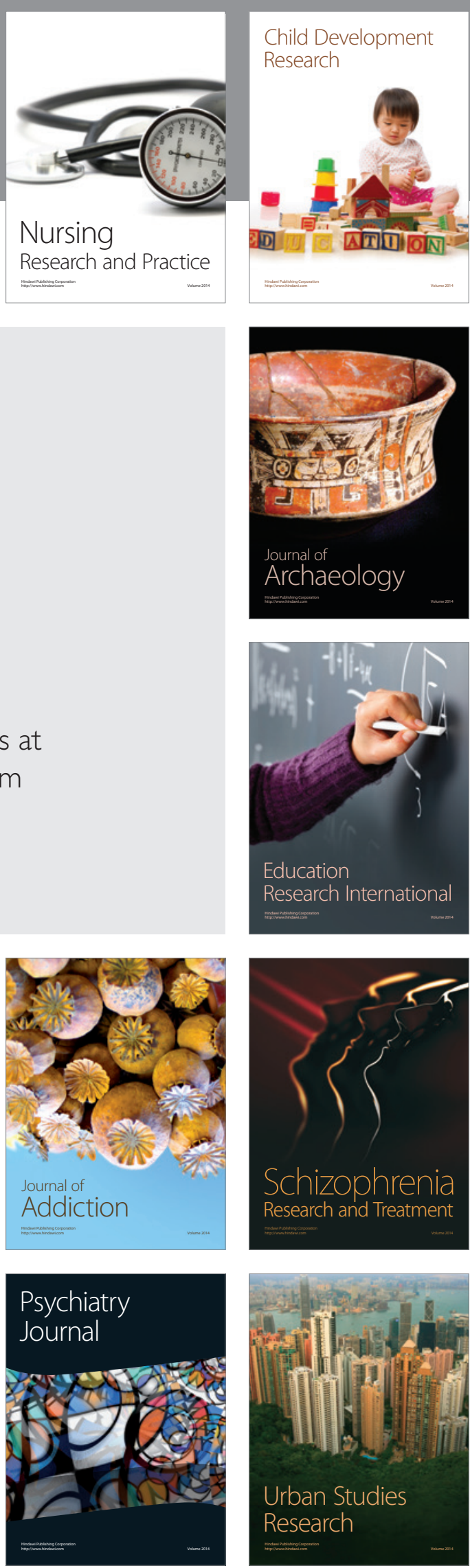